\title{
Exposição e significação: uma análise sobre os retratos de prisioneiros do Camboja ${ }^{1}$
} Exhibition and meaning: an analysis of the Cambodian prisoners portraits

Daniela Bracchi

${ }^{\mathrm{E} E s t e}$ artigo faz parte da pesquisa conduzida no grupo de pesquisa "Fotografia Contemporânea" do Laboratório de Fotografia do Núcleo de Design da UFPE.

${ }^{2}$ Possui graduação em Psicologia pela Universidade Federal da Bahia, Mestrado em Comunicação e Semiótica pela PUC-SP e Doutorado em Semiótica pela USP. Professora Adjunta do curso de Design da Universidade Federal de Pernambuco, Centro Acadêmico do Agreste. Líder de pesquisa do grupo sobre Fotografia Contemporânea. E-mail: bracchi@gmail.com 
Resumo: este artigo busca discutir as diferenças nos modos de exibição de fotografias como produção de formas distintas de compreensão das imagens. O exemplo dos retratos de prisioneiros políticos do Camboja é o ponto de partida para se compreender que as escolhas expográficas relativas a essas imagens podem valorizá-las tanto do ponto de vista estético quanto político. Apresenta-se, portanto, diferentes níveis de análise que organizam melhor a reflexão sobre o sentido das imagens em seu contexto expográfico.

Palavras-chave: fotografia; retrato; níveis de análise; semiótica.

Abstract: this article discusses the differences in photo exhibitions as production of different ways of understanding the images. The example of the portraits of political prisoners in Cambodia is the starting point for understanding that the exhibition choices relating to these images can value them in a political and artistic sense. Is presented therefore different levels of analysis that organize best the reflection on the image analysis and its expographic context. Key words: photography; portrait; analysis levels; semiotics. 


\section{Introdução}

"O cavalo de Troia que penetrou o museu é a fotografia."

Thierry De Duve

Atualmente, proliferam-se estudos que buscam compreender a imagem fotográfica como objeto cultural, considerada na diversidade dos usos e modos pelos quais circula. Mesmo disciplinas que antes investigaram uma classificação baseada na ontologia da imagem fotográfica, tal como a semiótica, caminham hoje para a compreensão do sentido construído nos diversos modos de se mostrar imagens. Entende-se, por exemplo, que certas imagens postadas em redes sociais cumprem a função de atestar uma presença e pertença a uma comunidade de gostos enquanto outros circuitos, como museus e galerias, propõem uma fruição estética da fotografia como modo prioritário de se relacionar com o caráter artístico das imagens.

A diversidade desses usos já havia sido notada pela pesquisadora americana Susan Sontag, que na década de 1980 alertou sobre uma dessas inusitadas funções da fotografia. Haveria um uso "talismânico" (SONTAG, 1986, p.25), no qual a imagem participa de uma busca por tornar mais próxima a presença do retratado. Levamos imagens de entes queridos na carteira como tentativa de evocar a proximidade emotiva de sua presença, enquanto a mesma imagem $3 \times 4$ serve como identificação dos traços fisionômicos do indivíduo para as instituições onde circula.

Pode-se alcançar, ainda, o sentido político dessas imagens de identificação. No filme de Sebastián Moreno, La ciudad de los fotógrafos (2006), as fotos 3x4 dos desaparecidos políticos durante a ditadura chilena habitam altares dentro das casas de famílias, construindo um lugar de proximidade emocional com essas pessoas. Ao mesmo tempo, os parentes desses desaparecidos, especialmente as mães, levam essas imagens alfinetadas ao peito em suas aparições em cerimônias oficiais e manifestações políticas. Expõe-se aí não apenas a intensidade emotiva da perda, mas a insistência em tornar essas imagens públicas também expressa o clamor político pela justiça.

Percebe-se, portanto, a dificuldade de se atestar a especificidade do fotográfico como dada a priori. Isso porque a fotografia assume funções diferentes em domínios sociais específicos. São papéis sociais que se fundam sobre práticas interpretativas, construindo assim um campo de expectativas e normas que contribuem para a fundação dos gêneros das imagens (diferenciando, portanto, os estatutos artístico, científico, publicitário, etc.). Concordamos, portanto, com a afirmação do semioticista francês Jean-Marie Floch (FLOCH, 1987, p.15), de que "A Fotografia 
faz mais sentido quando pensada enquanto fotografias, entendidas na sua pluralidade e enquanto objeto cultural que participa de práticas interpretativas diversas".

A partir do entendimento do aspecto múltiplo da fotografia, porque dependente das práticas sociais, o termo Semiótica da Fotografia é proposto só recentemente, em 2011, na publicação de Pierluigi Basso Fossali e Maria Giulia Dondero (DONDERO; BASSO FOSSALI, 2011), na qual o ressurgimento de uma Semiótica da Fotografia entende este objeto de estudo a partir de níveis de análise, dentre os quais considera-se as práticas das quais participam e o contexto onde circulam, de modo a reafirmar ou subverter modos de interpretação que vão sendo cristalizados no seio social.

Deve-se considerar que tais níveis são estabelecidos seguindo a esteira da investigação sobre os textos visuais de acordo com um ponto de vista que parte de bases estruturalistas para considerar as imagens enquanto construções discursivas mais abrangentes do que a identificação sígnica das figuras presentes na imagem. Uma maior relevância é dada ao nível de análise dos textos-enunciados e os desenvolvimentos atuais da semiótica da fotografia colocam atenção sobre a enunciação de tais textos visuais, de modo a considerar aspectos como as marcas de subjetividade no modo de construir a imagem. Segue-se, ainda, a consideração da fotografia como objeto, compreendida em sua materialidade. Isso significa resgatar o papel da textura, pois esse formante plástico se mostra como um importante indicador: das marcas de uso, do tempo de produção e do papel da fotografia como objeto em meio a outros (sua integração no álbum fotográfico, sua exposição museográfica, etc.).

Uma determinada situação de exposição de uma fotografia faz da imagem uma participante de uma prática social em que lhe é atribuído um papel. A cena predicativa diz respeito a esses papéis da imagem que dependem grandemente do contexto em que está inserida. Num museu, por exemplo, costuma estar envolvida num convite à apreciação estética, enquanto a mesma imagem na capa de jornal cumpre outro papel atestando a ocorrência de um fato e trazendo credibilidade à notícia.

A subversão do papel actancial da fotografia é um dos indicativos de que existe um nível maior de análise, o das estratégias, que se preocupa com as estabilizações e rupturas de práticas. Aquelas que se apresentam contínuas ao longo da história são responsáveis pela formação dos estatutos (os tipos de imagem e as expectativas quanto ao modo de serem interpretadas), que podem ser subvertidos por determinados artistas quando constroem textos isolados ou mesmo por museus que definem seu modo de exposição.

Com tal amplitude de níveis de análise, propõem-se compreender melhor a 
construção da significação nas fotografias de identificação que aparecem no contexto do genocídio no Camboja. Tais imagens encontram seu sentido expandido, ou mesmo subvertido, a partir da relação estabelecida entre elas e seu co-texto expográfico. Certamente esta análise não busca esgotar o conjunto de situações em que essas imagens apareceram no âmbito artístico, mas lança uma luz sobre a compreensão do papel da expografia a partir de casos específicos que permitem pensar na variação de situações em que as fotografias se dão a ver.

\section{A exposição das imagens e suas diferentes valorizações}

Escolhemos nos deter aqui na análise dos vários modos de exibição de imagens que chamam a atenção por terem uma grande carga emotiva, estética e política. A variabilidade no modo como essas imagens são apresentadas traz consequências importantes quanto ao modo de compreender e sentir tais fotografias.

As imagens de prisioneiros feitas durante a ditadura do Khmer Vermelho em um campo de extermínio no Camboja serviam a princípio como identificação dos capturados, que tinham a fotografia e uma biografia arquivada nas prisões do país. Depois de fotografados, os prisioneiros eram interrogados, torturados e executados. Após a invasão do país pelo Vietnã, a mais secreta dessas prisões é transformada em um museu. Tuol Sleng havia sido uma escola antes de se configurar numa prisão, passando a ser, em 1980, um local que preserva e expõe as marcas do genocídio ocorrido de 1975 a 1979. Expostas no local onde a barbárie aconteceu, essas imagens reconstroem um pouco da experiência dos fotografados e tornam mais encarnada a dor que tais retratos podem guardar. Na Figura é possível perceber detalhes do lugar e do modo de exposição dessas fotos no museu do Camboja.

${ }_{3}^{3}$ Disponível em http://www.niod.nl/sites/niod.nl/files/styles/colorbox/public/Photographs\%20of\%20 prisoners\%20at\%20S-21\%20\%28now\%20the\%20Tuol\%20Sleng\%20Genocide\%20Museum\%29.\%20 DCCAM.jpg?itok=hxDtpHvb. Acesso 21/07/2016. 


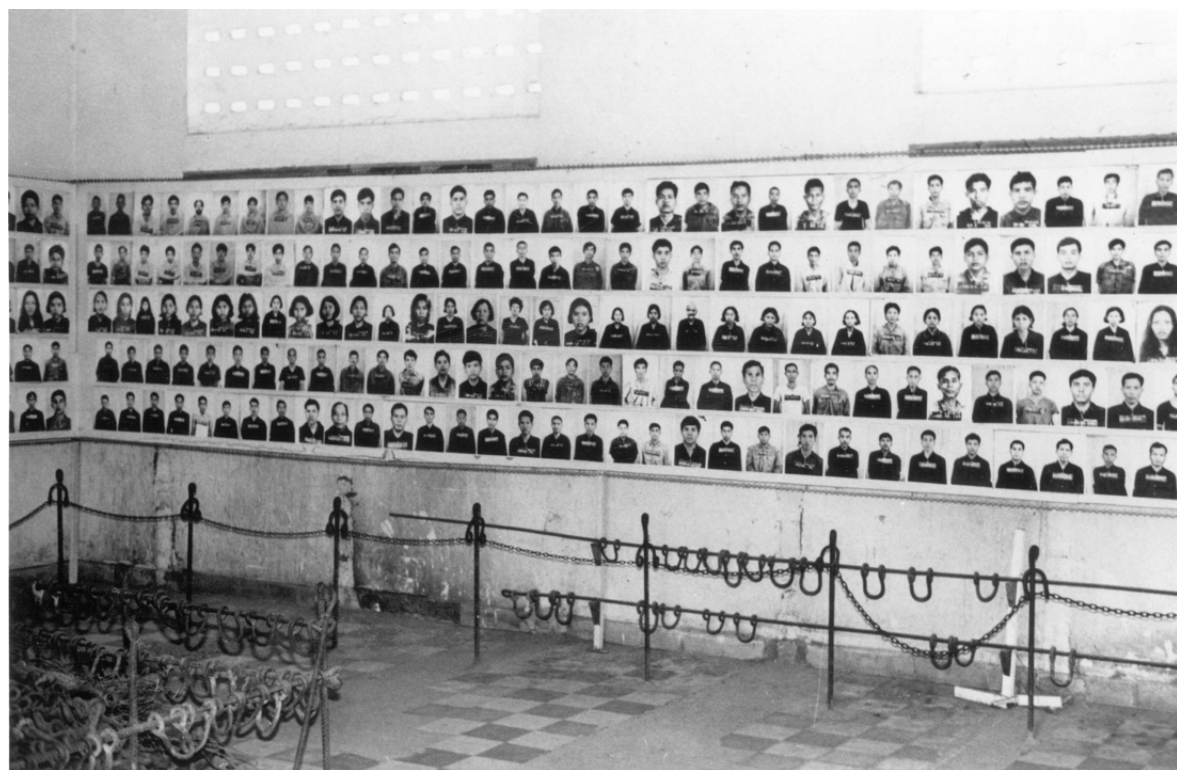

Figura 1: Fotos dos prisioneiros expostas em Tuol Sleng.

Em 1997, vinte e duas dessas fotografias foram adquiridas e ganharam as paredes da exposição Photographs from S-21:1975-1979, no MOMA de Nova York. A galeria onde estavam expostas estas fotos no museu propunha uma colaboração entre o departamento de fotografia e o de educação, e o MOMA indica no seu comunicado de imprensa que os visitantes são convidados a sentarem e refletirem. $\mathrm{O}$ comunicado continua, no entanto, falando não mais sobre os acontecimentos históricos e políticos, nem mesmo sobre a colaboração dos Estados Unidos para tal guerra civil, mas sim sobre a importância de se compartilhar o interesse por determinadas fotografias e episódios relativos à história da fotografia e termina por exaltar a rica coleção de imagens pertencentes ao MOMA.

Percebe-se, portanto, que o museu coloca em primeiro plano uma discussão sobre a linguagem artística, evidente já na escolha por expor apenas as fotografias e não os outros objetos de tortura pertencentes ao contexto onde essas imagens foram geradas. O museu considera, portanto, apenas a exibição da fotografia e estimula a re-

${ }^{4}$ De Duve (2008, p.66) explica: "'S-21' é o nome de um antigo colégio do bairro de Tuol Sleng, em Phnom Penh, que Pol Pot transformou em centro de tortura e campo de extermínio. Entre 1975 e 1979, 14.200 pessoas foram brutalmente executadas no S-21, no próprio local ou em campos próximos. Existem sete sobreviventes. Em razão do regulamento e da burocracia do regime, todo homem, mulher e criança que entrava no centro era fotografado antes de ser morto. Para desempenhar essa função hedionda, um membro do Khmer Vermelho de 15 anos de idade, chamado Nhem Ein, foi enviado a Xangai para estudar fotografia e, um ano depois, era promovido a "fotógrafo-chefe" no S-21, com cinco funcionários sob seu comando. Quando os vietnamitas libertaram o centro em 1979, cerca de 6.000 negativos foram achados". 
flexão sobre a história desse meio, deixando clara a posição de valorização da imagem no contexto artístico, enquanto outros artefatos da cultura ficam de fora da exposição. Tal postura do MOMA de compreensão da arte a partir de uma separação e diferente valorização da linguagem e materialidade utilizada para produção da obra é recorrente na história do museu e são famosos os episódios nos quais obras compostas por materiais diversos, como One and Three Chairs (uma e três cadeiras) (1965), de Joseph Kosuth, são desmembradas após sua exposição. Enquanto o objeto cadeira foi enviado ao departamento de design, a fotografia foi arquivada no departamento de fotografia e a definição de dicionário enviada à biblioteca.

Criado em 1929 para expor a arte moderna e ressaltar a identidade americana, o museu se viu constantemente em meio à polêmica não só de ter uma visão isolada dos meios artísticos, mas também de se furtar a expor obras com forte conteúdo político. O exemplo mais célebre é a recusa do museu em financiar And babies (e bebês) (1969), do grupo AWC, pois a obra claramente se colocava como contrária à guerra do Vietnã. No ano seguinte, no entanto, a instituição cria uma exposição na qual o trabalho do artista Hans Haacke surpreendeu o próprio museu no conteúdo político da obra revelada de última hora e que questionava a opinião dos visitantes sobre o apoio político do governador Rockefeller (um dos maiores sócios do museu) ao presidente Nixon.

Vale lembrar, então, que tal museu se configurou ao longo de sua existência como um local para colecionar e expor arte, conforme ressalta Thierry De Duve (DE DUVE, 2008, p.70), e "não para promover o dever da memória ou testemunhar as monstruosidades geradas pela insanidade política”. Mader explica a ambientação clean adotada pelos curadores, que insinuava o possível valor estético dessas imagens:

As 22 fotos exibidas no MOMA não traziam legendas explicativas, atribuição de autoria ou identidade das vítimas. O texto de apresentação mencionava o Khmer Vermelho e quatro anos de uma desastrosa guerra civil’, omitindo o papel desempenhado pelos Estados Unidos na destruição do Camboja e na sustentação do Khmer Vermelho após a intervenção do Vietnã. (MADER, 2011, p.48).

Ainda que o caráter serial e desindividualizado das imagens expostas possa evocar o sentido desumano e serial do extermínio desses prisioneiros, sente-se a ausência de outros elementos que evoquem tanto cognitivamente (no texto de exposição, por exemplo) quanto sensivelmente o contexto de barbárie no qual essas imagens foram produzidas. Não podemos dizer, contudo, que o MOMA tinha o intuito de alienar voluntariamente o potencial político do trabalho, mas o ponto de vista de 
uma estética modernista adotado constantemente pelo museu dirige a prática interpretativa e questiona a noção institucional da arte e o próprio ethos ${ }^{5}$ do fotógrafo Nhem Ein:

\begin{abstract}
Se aquelas fotografias eram arte, sendo a arte patrimônio da humanidade e os artistas seus porta-vozes no domínio estético, então Nhem Eim teria de ser considerado um artista e, portanto, um legítimo representante da humanidade - noção que beirava a obscenidade e motivava fobias e denegações entre os curadores. (MADER, 2011, p.49).
\end{abstract}

De fato, o museu adquire oito imagens de Nhem Eim e o coloca na sua lista de artistas. Outro fator que corrobora o entendimento dessas imagens como valorizadas em primeira instância por sua carga artística e estética é a busca de efeito de neutralidade constantemente adotada pela expografia do museu. As regras arquitetônicas para tal efeito de sentido de neutralidade podem ser rígidas. No caso dos museus, inclui não só a pintura branca das paredes, mas janelas lacradas e o teto como única fonte de luz, chão de madeira polido ou mesmo acarpetado para que se possa fruir as obras sem interferência externa de som ou luz sobre as imagens. Tal sistema de visibilidade da arte é denominado de "Cubo Branco" por O'Doherty (O’DOHERTY, 1999, p.4) e a ideologia modernista de valorização expográfica das obras em si mesmas foi criticada por Douglas Crimp (CRIMP, 2005), pois sugere a chancela institucional tanto do que seria arte quanto do modo de fruição estética desligado de outras esferas que a obra pode participar (sociais, políticas, psicológicas, etc.).

Colocadas sobre um fundo que busca realçar os contrastes cromáticos e eidéticos das figuras aí expostas, essas imagens deixam em segundo plano uma compreensão mais política e humanista quanto ao percurso e o destino dos fotografados. As imagens são arrancadas de seu contexto histórico original para serem inseridas na discussão sobre a linguagem fotográfica. Não se nega a importância de tal reflexão, mas devemos considerar que são imagens que se situam na fronteira de um limite ético quanto a sua apreciação estética e que terminam por percorrer um caminho no qual as práticas que contextualizam sua interpretação foram se modificando.

Percebe-se, assim, o quanto é importante que o Museu do Genocídio, no Camboja, exponha próximo dessas imagens os instrumentos de tortura, as grades com a pungência do arame farpado e as celas como espaços exíguos. Esses elementos constituem um percurso claustrofóbico a ser percorrido pelo visitante como parte da experiência de estar no lugar onde essas fotografias foram produzidas. A conservação

${ }^{5} \mathrm{O}$ ethos é aqui referido como um modo próprio de presença no mundo. É considerado a partir das estratégias enunciativas que o enunciador constrói, demonstrando seu estilo. Este último é definido por Norma Discini (DISCINI, 2004, p.7) como "um conjunto de características da expressão e do conteúdo que criam um ethos". 
dos espaços de tortura constitui um modo de expor as imagens pronto a lembrar o visitante sobre a história de genocídio do qual essas imagens participam. Há, portanto, uma valorização estética da expografia que mantém implicações éticas sobre o modo de fruição dessas imagens. Trata-se de considerar a situação expositiva como um discurso não isento e capaz de direcionar o modo de interpretação das fotografias de identificação dos prisioneiros.

Uma visita ao site do Museu do Genocídio permite apontar, ainda, a constante valorização do componente artístico dessas imagens. A fotografia presente na capa do site (Figura $2^{6}$ ) explora a plasticidade presente na deterioração química do material fotográfico. Realça-se a beleza da pátina do tempo que, quase como a figura de uma cicatriz, impõe-se à figura humana e torna mais opaco o jogo de olhares entre o personagem da foto e quem o olha.

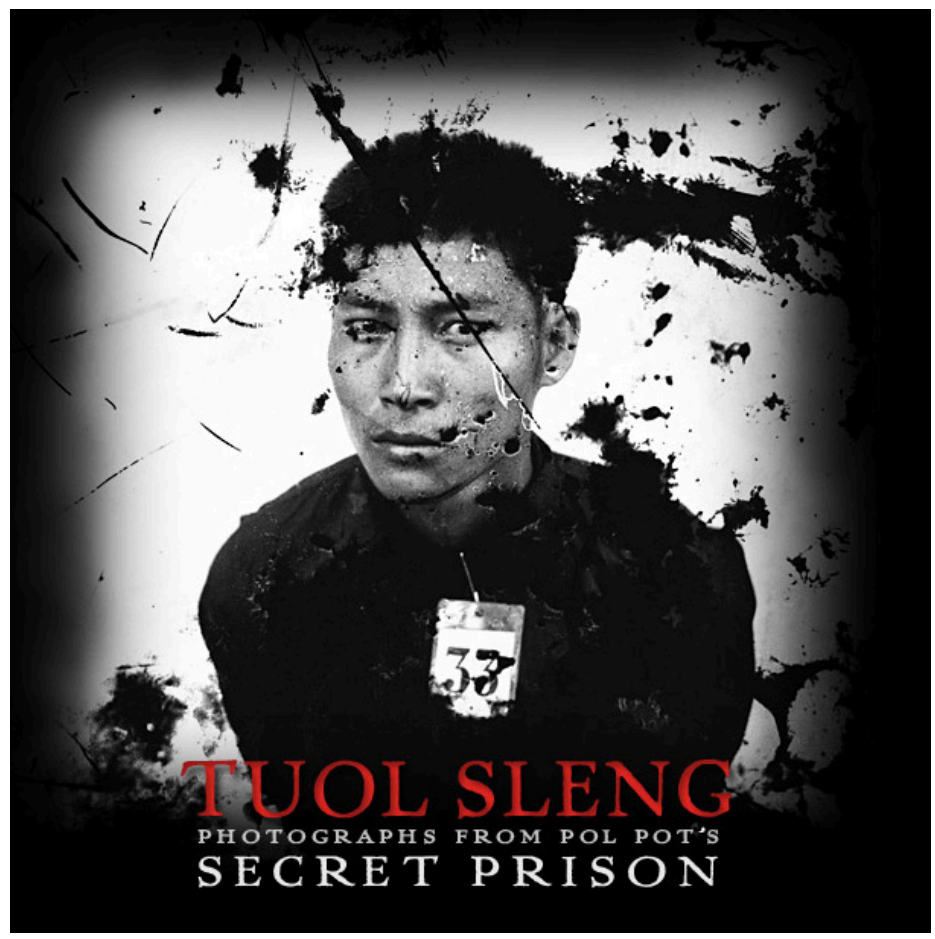

Figura 2: Fotografia de abertura do site do Museu do Genocídio.

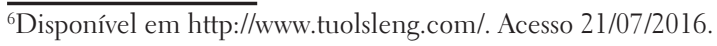


A mídia digital atua em continuação a uma prática museológica de exposição de obras de arte fundada no modelo do "Cubo Branco", subtraindo todas as interferências para propiciar uma apreciação das qualidades plásticas da obra. Entende-se, portanto, que o espaço expositivo pode ser construído tanto digitalmente quanto arquitetonicamente no museu e funciona como um co-texto que dialoga com as imagens e participa do modo como serão compreendidas. A situação semiótica da qual essas imagens participam cristalizam as práticas interpretativas que direcionam sua compreensão e o modo como são sentidas pelo enunciatário. Tais situações devem ser entendidas como um contorno mais ou menos explicativo do texto.

Antes entendidas sob a designação vaga de contexto, a situação de que a foto participa merece ser considerada como um outro conjunto significante que merece a atenção da disciplina semiótica como constituindo um novo nível de pertinência para se considerar a construção do plano de conteúdo. Desse modo, importa à semiótica o estudo da expografia, pois entende-se como importante o modo como as imagens são dispostas em uma exposição ou mesmo no livro publicado pelo artista. A fotografia não é, portanto, reconhecida como campo autônomo de análise com base nas particularidades inerentes a sua gênese, mas sim nas constantes relações com outros discursos (entre os quais incluímos aqui o expográfico) capazes de direcionar as práticas interpretativas da imagem.

Não poderíamos deixar de comentar, portanto, o modo com essas imagens aparecem no artigo de Mader (MADER, 2011) que critica o próprio modo de valorização estética das fotografias. Algumas páginas inteiras da reportagem exibem apenas uma grande imagem de identificação, valorizando o componente estético do retrato e propondo uma experiência de estar frente a frente, próximo das proporções de uma escala humana, com a imagem do prisioneiro que olha diretamente para a câmera. É reconstruída, portanto, uma experiência de estar cara a cara com o retratado e interpelado pelo seu olhar, valorizando a carga emotiva dessas imagens e tornando-as um ponto de partida sensível para um questionamento sobre o horror do genocídio. Além disso, a reportagem destaca cromaticamente trechos de depoimentos dos sobreviventes. Posicionados próximos das imagens, esses dizeres trazem ao leitor uma imersão maior no mundo subjetivo de tais indivíduos que se questionam "Onde estou? O que fiz de errado? De que me acusam?” (MADER, 2011, p.30).

Ao longo da publicação encontram-se também retratos que deixam ver mais as condições de sua produção (o suporte para o corpo que imobiliza essas pessoas, as algemas e correntes que as prendem ao local de tortura, etc), como ilustrado na parte 1 e 2 da Figura 3. Há também imagens que localizam melhor o uso desses retratos, 
como a exposição da biografia do prisioneiro forjada pelo campo de extermínio, na qual se localiza o lugar do retrato na documentação produzida na época (parte 3 da figura 3).

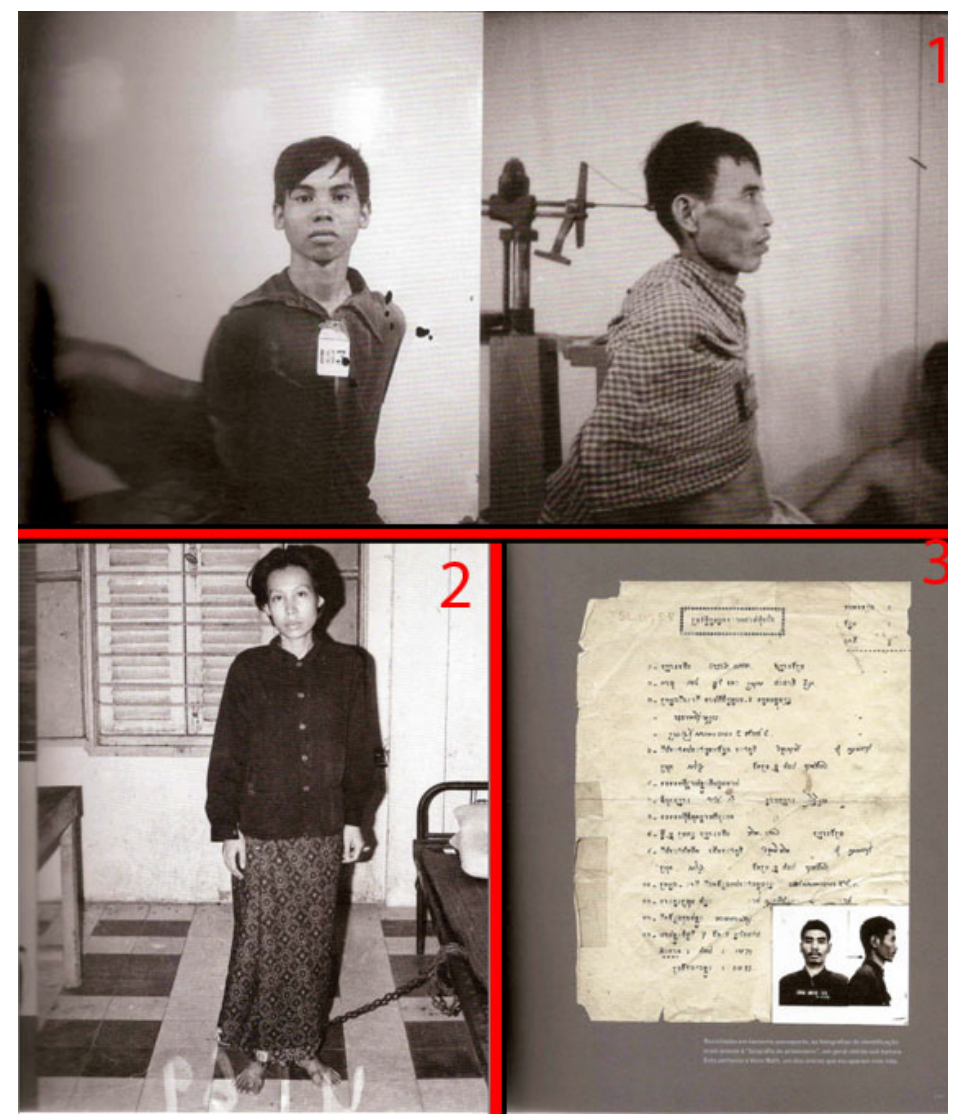

Figura 3: imagens expostas na reportagem de Hugo Mader para a revista Zum, 2011. Fonte: MADER, Hugo. Na antessala da morte: retratos do genocídio do Camboja.

Entende-se, portanto, que os modos pelos quais essas imagens se dão a ver em instituições como museus e galerias, ou ainda o modo como são expostas em livros, catálogos e revistas da área permitem compreender os termos nos quais se dá o convite para que o enunciatário entre em contato com o texto fotográfico. No caso da reportagem de Hugo Mader, há tanto a presença de componentes sensíveis presentes no enfrentamento cara a cara dos retratos em tamanho de página cheia, quanto apresentação de documentos e áreas do entorno da imagem que complementam a presença não só das pessoas dos retratos, mas do local onde foram produzidos e que deixam importantes pistas sobre a situação de construção dessas imagens. 


\section{Considerações finais}

Ainda que a exposição museológica nos termos modernistas dos retratos de prisioneiros executados possa ser condenável do ponto de vista humanista, é interessante constatar que tal estratégia se mostra típica do embaralhamento dos estatutos realizado pela arte contemporânea. Imagens das mais diversas origens são trazidas ao contexto museológico de modo a contestar não só o caráter artístico das imagens, mas o próprio papel do museu e sua chancela artística.

O exemplo visto acima, sobre os retratos dos prisioneiros do campo de concentração do Camboja, pode ser melhor compreendido quando considerada a mudança de estatuto de imagens informativas sobre a feição dos prisioneiros, usadas no seu registro ao ingressar no campo de concentração, para fotografias valorizadas plasticamente dentro do contexto do museu. Essas imagens alertam para a importância de se considerar a dependência do regime interpretativo sob o qual circulam essas imagens, e das práticas cristalizadas de que participam ou mesmo que subvertem.

Uma valorização majoritariamente estética das imagens fotográficas pode ser um caminho perigoso adotado por instituições museológicas, mas a crítica não se restringe a tal contexto de exposição. Um tema político exposto num livro de fotografias sem texto que o ancore, poderia igualmente correr o perigo de expor unicamente o caráter estético das imagens. Parece, portanto, haver sempre uma intricada relação entre o valor artístico e político da fotografia que reflete maneiras de circulação das imagens e modos distintos de organização de discursos. Está em jogo aqui não só uma noção de beleza e de valor do objeto artístico, mas a exaltação de um modo de perceber o mundo e se relacionar com os objetos mais ou menos engajados politicamente.

Esperamos ter mostrado, por meio do célebre exemplo das fotografias de prisioneiros, que a imagem fotográfica não se caracteriza socialmente apenas pelas formas visuais que exibe. Deve-se considerar os contextos mais amplos em que é exposta, pois tais modos de exibição podem concorrer para o direcionamento da maneira como serão sentidas e compreendidas nas diferentes esferas onde circulam. 


\section{Referências bibliográficas}

CRIMP, D. Sobre as ruínas do museu. São Paulo: Martins Fontes, 2005.

DE DUVE, T. A arte diante do mal radical. Ars, São Paulo, n. 13, 2008.

DISCINI, N. O estilo nos textos: história em quadrinhos, mídia, literatura. 2. ed. São Paulo: Contexto, 2004.

DONDERO, M; BASSO FOSSALI, P. Sémiotique de la photographie. Limoges: PULIM, 2011.

FLOCH, J. Les Formes de L'empreinte. Périgueux: Pierre Fanlac, 1987.

FREIRE, Cristina. Poéticas do processo: arte conceitual no museu. São Paulo: Iluminuras, 1999.

MADER, H. Na antessala da morte: retratos do genocídio do Cambodja. IN: ZUM: Revista de Fotografia. Vol.1.São Paulo: Instituto Moreira Salles, 2011, p.30.

O'DOHERTY, B. No interior do cubo branco: a ideologia do espano na Arte. São Paulo: Martins Fontes, 1999 (original inglês de 1976).

SONTAG, S. Ensaios Sobre Fotografia. Lisboa: Dom Quixote, 1986.

submetido em: 30 ago. 2015 | aprovado em: 19 jan. 2016. 